\title{
Study on the Manufacture of Reserve Battery. VI. Study on the Electrolytes for Reserve Battery
}

\author{
Yoshio YoкотA \\ Mizuguchi Laboratory, Tokyo Institute of Technology, Ookayama, Meguro-ku, Tokyo and \\ Toyo Special Paint Co., 1503, Mefuki, Noda, Chiba
}

In general, electrolytes for batteries have inconsistent properties, namely, without self-corrosion (non-electromotive resolution) they easily dissolve anode metal during discharge.

Moreover, conductivity should be high in order to lower the internal resistance of the battery as much as possible.

The author will express the conditions required for the electrolyte of aluminum "Reserve Battery", summarizing from the results of the experiments in this report and the previous Reports (I) (V).

1) The reasons why $\mathrm{NaCl}$ alone or mixture of $\mathrm{NaCl}$ and sulfamic acid is selected as the most practical electrolyte are as follows:

a) No chemical change during preservation.

b) Less hygroscopic and good resolution at impregnation.

c) High conductivity.

d) Easily dissolves anode aluminum electromotively, but self-corrosion of anode is considerably small.

e) Low price.

f) Sodium chloride alone is required for the electrolyte of the aluminum battery of small current and long life (small self-corrosion amount of anode aluminum).

g) The mixture of $\mathrm{NaCl}$ and sulfamic acid is required for the electrolyte of the aluminum battery of large current and short life (large reactivity with anode).

2) For cold-proof electrolyte, anti-freezing reagent such as methanol should be added to the impregnating liquid rather than the selection of electrolytes.

3) By the construction of aluminum battery and its short life, it can be concluded that the evaporation of water in the electrolyte by the heat generation of battery gives almost no effects on its discharging power. However, sometimes the reagents such as glycerines which elevate b.p. should be added to the impregnating liquid.

\section{Introduction}

Electrolytes used for "Reserve Battery" in olden times were sulfuric acid solutions ${ }^{1)}$ in general, and sometimes perchlorates ${ }^{21}$. In these days, however, pure water has been very often used for silver-chloridemagnesium battery ${ }^{3)}$ or cuprous chloride-magnesium batter $y^{4)}$ (both are very popular at present), and sometimes sea-water has been used.

The author considered that it was most convenient for practical use to impregnate aluminium "Reserve Battery" with pure water.

Previously in Report (I), aq. solutions of caustic soda, sulfuric acid, tartaric acid, sodium chloride, etc. were used as electrolytes for aluminum "Reserve Battery", and corrosion rate of aluminum anode and output of current generation were examined for preliminary experiments. Moreover, in Report (V), $\mathrm{NaCl}$ alone or mixed solution of $\mathrm{NaCl}$ and sulfamic acid was used as electrolyte for cathode material, and the relation between output of current generation or current density and potential was investigated.

From these results, sodium chloride alone or mixture of sodium chloride and sulfamic acid was 
selected out as the practical electrolyte for the following reasons: not only its electro-chemical properties were excellent, but it was very easy to be dried when being absorbed into an electrolyte holder (such as filter paper) and almost no chemical reaction happened during preservation, moreover, it was immediately dissolved after the impregnation of water.

In this report, such properties as conductivity, b.p., etc. were investigated with solutions of various concentrations of the above electrolyte used, and were also investigated the relation between the composition of electrolyte and the amount of self-corrosion of anode metal.

Dissimilar to other general batteries, when "Reserve Battery" is used at low temperature, the liquid used for its impregnation should be anti-freezing rather than its electrolyte, namely, in "Reserve Battery" the freezing of electrolyte should not happen during discharge for its self-heating at the end of chemical reaction.

Therefore, some suitable anti-freezing reagent should be added to the water for impregnation when "Reserve Battery" is used at low temperature.

The author prepared the electrolyte to which anti-freezing reagent was added, and investigated on the relation between the composition and conductivity, and also b.p., etc. of the electrolyte for low temperature.

\section{Experiment and Discussion}

\subsection{Materials for Experiment}

Electrolyte: Electrolytes of various compositions were prepared from reagents of JIS 1st Grade.

Test pieces of aluminum: Aluminum of various compositions, only rolled but not annealed, were cut to pieces of $10 \times 20 \mathrm{~mm}$ and $3 \mathrm{~mm}$ thick for use.

The compositions of aluminum used as test pieces are shown in Table 1.

\subsection{Method of measurement}

Conductivity: Kohlrausch bridge was used for the measurement as in general. The baths for measuring conductivity were immersed for $1 \mathrm{hr}$ in thermostats of various temperatures shown in the other table, and then measurements were made.

Table 1 Composition of Aluminum

\begin{tabular}{c|c|c|c|c|c}
\hline \hline \multirow{2}{*}{ Composition } & \multicolumn{5}{|c}{ Test piece of aluminum } \\
\cline { 2 - 6 } & $\mathrm{A}$ & $\mathrm{B} *$ & $\mathrm{C}^{* *}$ & $\mathrm{D}$ & $\mathrm{E}$ \\
\hline $\mathrm{Al}$ & 99.997 & 99.94 & 99.44 & 98.65 & 95.275 \\
$\mathrm{Cu}$ & 0.0017 & - & - & 0.01 & 0.0016 \\
$\mathrm{Si}$ & 0.0010 & 0.026 & 0.22 & 0.06 & 0.0010 \\
$\mathrm{Fe}$ & 0.0008 & 0.032 & 0.34 & 0.08 & 0.0006 \\
$\mathrm{Zn}$ & - & - & - & 1.00 & 4.72 \\
$\mathrm{Mn}$ & - & - & - & - & - \\
$\mathrm{Mg}$ & - & - & - & - & - \\
$\mathrm{In}$ & - & - & - & 0.2 & - \\
\hline
\end{tabular}

* High purity in commercial

** Normal purity grade in commercial

Conductivity at lower temperature was measured after being settled for, a definite time in a thermostat bath, or Dewar vessel in which dry ice was added into methanol. Temperature was controlled by the addition of dry ice (within nearly $\pm 2^{\circ} \mathrm{C}$ ).

Freezing-point: Freezing-points of electrolytes for ordinary temperature were measured in a low temperature thermostat of ice and calcium chloride, and those for low temperature were measured in a low temperature thermostat of dry ice and methanol. In the both cases, the measurements were made by the same methods as cryoscopic method.

Boiling-point: Each $150 \mathrm{cc}$ of electrolytes of various composition was placed in a beaker of $150 \mathrm{cc}$, and its boiling point was measured by heating under the atmospheric pressure.

Corrosion rate of aluminum: Test pieces of aluminum were polished with $\# 600$ emery paper just before dipping into the electrolytes, washed with distilled water, dehydrated with absolute methanol, and was weighed by chemical balance after drying.

Each test pieces was placed in a conical flask with $100 \mathrm{cc}$ of various composition of electrolytes, slightly sealed with a rubber stopper, and settled for seven days at ordinary temperature.

The dipped test pieces were taken out and scraped with a brush in running water to remove cor- 
rosion products, and then dehydrated with absolute methanol and weighed after drying.

$p H$ : Measurement was made at room temperature with a glass electrode.

\subsection{Experimental Results}

\subsubsection{Electrolyte for ordinary temperature}

\section{a) On composition of electrolytes and their relation with conductivity, boiling-point, and $\mathrm{pH}$}

The results obtained are summarized and shown in Table 2 .

Table 2 Relation Between Composition of Electrolyte and $\mathrm{pH}$, b.p. or Conductivity etc.

\begin{tabular}{c|c|c|c|c|c|c|c}
\hline \hline $\begin{array}{c}\text { Composition of } \\
\text { Electrolytes }(M)\end{array}$ & $\mathrm{pH}$ & $\begin{array}{c}\text { Boiling } \\
\text { point } \\
\left({ }^{\circ} \mathrm{C}\right)\end{array}$ & $\begin{array}{c}\text { Freezing } \\
\text { point } \\
\left({ }^{\circ} \mathrm{C}\right)\end{array}$ & \multicolumn{3}{|c}{$\begin{array}{c}\text { Conductivity } \\
\left(\Omega^{-1} \mathrm{~cm}^{-1}\right)\end{array}$} \\
\cline { 1 - 4 } $\mathrm{NaCl}$ & $\mathrm{NH}_{2} \mathrm{SO}_{3} \mathrm{H}$ & & $25^{\circ} \mathrm{C}$ & $35^{\circ} \mathrm{C}$ & $45^{\circ} \mathrm{C}$ \\
\hline 0.1 & - & 6.70 & 101 & 0 & 0.0102 & 0.0118 & 0.0150 \\
0.3 & - & 6.55 & 101 & -1 & 0.0287 & 0.0366 & 0.0420 \\
0.5 & - & 6.45 & 101.5 & -1.5 & 0.0478 & 0.0565 & 0.0625 \\
0.7 & - & 6.50 & 102 & -2.2 & 0.0649 & 0.0763 & 0.0840 \\
1.0 & - & 6.55 & 102.5 & -3.5 & 0.0862 & 0.0961 & 0.1111 \\
1.5 & - & 6.45 & 103 & -5.5 & 0.1041 & 0.1449 & 0.1613 \\
\hline 0.5 & 0.1 & 1.50 & 102 & -2.2 & 0.0617 & 0.0826 & 0.0909 \\
$"$ " & 0.3 & 1.20 & 102.5 & -2.2 & 0.0840 & 0.1099 & 0.1219 \\
\hline$"$ & 0.5 & 1.00 & 103.5 & -2.5 & 0.0980 & 0.1335 & 0.1492 \\
\hline
\end{tabular}

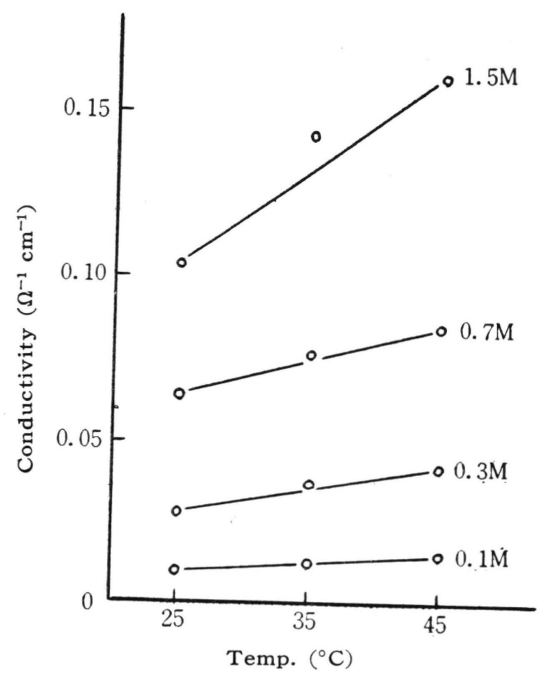

Fig. 1 Relation between the concentration of $\mathrm{NaCl}$, temp. and conductivity

The relation between temperature and conductivity for the electrolytes of sodium chloride alone is abstracted from Table 2 and shown in Fig. 1.

As seen in the above table the composition of electrolytes has no great effects on b.p., f.p. etc. from a practical viewpoint.

Moreover, it is reasonable that conductivity increased when sulfamic acid is added to sodium chloride.

\section{b) On composition of electrolytes and cor-} rosion rate of aluminum

The results obtained are shown in Table 3.

As seen in the above table self-corrosion amounts of aluminum of various compositions in the electrolytes of $\mathrm{NaCl}$ alone are negligibly small
Table 3 Relation Between the Composition of Electrolyte and Corrosion Rate of Aluminum

\begin{tabular}{c|c|c|c|c|c|c}
\hline \hline \multicolumn{2}{c}{ Electrolytes $(M)$} & \multicolumn{3}{|c}{ Corrosion rate of aluminum $\left(\mathrm{g} / \mathrm{m}^{2} / 100 \mathrm{~h}\right)$} \\
\cline { 1 - 7 } $\mathrm{NaCl}$ & $\mathrm{NH}_{2} \mathrm{SO}_{3} \mathrm{H}$ & $\mathrm{A}$ & $\mathrm{B}$ & $\mathrm{C}$ & $\mathrm{D}$ & $\mathrm{E}$ \\
\hline 0.1 & - & 0 & 0 & 0 & 0 & 0.44 \\
0.3 & - & 0.44 & 0 & 0 & 0.15 & 0.44 \\
0.5 & - & - & 0.15 & 0.30 & 0.30 & 0.59 \\
0.7 & - & - & 0 & 0 & 0.15 & 0.30 \\
1.0 & - & 0.15 & 0.15 & 0 & 0.15 & 0.44 \\
1.5 & - & 0.44 & 0.59 & 0.15 & 0.30 & 0.15 \\
\hline 0.5 & 0.1 & 7.52 & 6.34 & 134.82 & 82.60 & 94.40 \\
$" \prime$ & 0.3 & 5.61 & 5.90 & 355.48 & 155.76 & 152.52 \\
$" \prime$ & 0.5 & 5.61 & 6.64 & 548.70 & 156.35 & 371.70 \\
\hline
\end{tabular}
independent of their purities though the concentrations of $\mathrm{NaCl}$ are increased.

However, in the electrolytes containing acids, the purities of aluminum had great effects on corrosion amounts, and aluminum of $99.99 \sim 99.9 \%$ purity gave corrosion of $6 \mathrm{~g} / \mathrm{m}^{2} / 100 \mathrm{~h}$ while that of $99 \%$ gave 20 times more than that of high purity.

\subsubsection{On electrolytes for low temperature}

Electrolytes of various compositions for low temperature were prepared from water, sodium chloride, and any one of ethylene glycol and methyl alcohol as anti-freezing reagents, and measurements were made on conductivity and f.p. at $20^{\circ} \mathrm{C}$, and conductivity at low temperature.

The results of the measurements of conductivity and f.p. of electrolytes of various compositions at ordinary temperature, when ethylene glycol was used, are shown in Table 4, and those, when methyl alcohol was used, are shown in Table 5 .

Moreover, the relation between temperature and conductivity at low temperature is shown in Fig. 2. 
Table 4 Relation Between the Composition of Low Temperature Electrolyte and Conductivity, Freezing Poing

(Ethylene glycohol)

\begin{tabular}{c|c|c|c|c}
\hline \multicolumn{3}{c|}{ Electrolytes } & $\begin{array}{l}\text { Conducti- } \\
\text { vity } \\
\left(\Omega^{-1} \mathrm{~cm}^{-1}\right)\end{array}$ & $\begin{array}{l}\text { Freezing } \\
\text { point } \\
\left.{ }^{\circ} \mathrm{C}\right)\end{array}$ \\
\hline \multirow{2}{*}{30} & \multirow{2}{*}{70} & 0.5 & 0.0172 & -16.5 \\
& & 1.0 & 0.0244 & -20.5 \\
& & 1.5 & 0.0465 & -23.0 \\
\hline \multirow{3}{*}{35} & \multirow{2}{*}{65} & 0.5 & 0.0135 & -23.0 \\
& & 1.0 & 0.0201 & -24.5 \\
& & 1.5 & 0.0386 & -27.5 \\
\hline \multirow{3}{*}{40} & 60 & 0.5 & 0.0116 & -28.0 \\
& & 1.0 & 0.0167 & -29.5 \\
& & 1.5 & 0.0305 & -32.0 \\
\hline \multirow{3}{*}{45} & \multirow{2}{*}{55} & 0.5 & 0.0091 & -33.5 \\
& & 1.0 & 0.0137 & -34.0 \\
& & 1.5 & 0.0250 & -37.0 \\
\hline
\end{tabular}

Table 5 Relation Between the Composition of Low Temperature Electrolyte and Conductivity, Freezing Point (Methyl alcohol)

\begin{tabular}{|c|c|c|c|c|}
\hline & & & \multicolumn{2}{|c|}{ (Methyl alcohol) } \\
\hline \multicolumn{3}{|c|}{ Electrolyte } & \multirow{2}{*}{$\begin{array}{l}\text { Conducti- } \\
\text { vity } \\
\left(\Omega^{-1} \mathrm{~cm}^{-1}\right)\end{array}$} & \multirow{2}{*}{$\begin{array}{l}\text { Freezing } \\
\text { point } \\
\quad\left({ }^{\circ} \mathrm{C}\right)\end{array}$} \\
\hline $\begin{array}{l}\text { Methyl } \\
\text { alcohol }\end{array}$ & $\mathrm{H}_{2} \mathrm{O}(\%)$ & $\mathrm{NaCl}(M)^{*}$ & & \\
\hline \multirow{2}{*}{20} & \multirow{2}{*}{80} & 1.0 & 0.0541 & -22.5 \\
\hline & & 1.5 & 0.0869 & -28.0 \\
\hline \multirow{2}{*}{25} & \multirow{2}{*}{75} & 1.0 & 0.0502 & -28.5 \\
\hline & & 1.5 & 0.0775 & -35.0 \\
\hline \multirow{2}{*}{30} & \multirow{2}{*}{70} & 1.0 & 0.0451 & -35.5 \\
\hline & & 1.5 & 0.0714 & -44.0 \\
\hline \multirow{2}{*}{35} & \multirow{2}{*}{65} & 1.0 & 0.0403 & -42.5 \\
\hline & & 1.5 & 0.0602 & -48.0 \\
\hline \multirow{2}{*}{40} & \multirow{2}{*}{60} & 1.0 & 0.0369 & - \\
\hline & & 1.5 & 0.0565 & - \\
\hline \multirow{2}{*}{45} & \multirow{2}{*}{55} & 1.0 & 0.0357 & - \\
\hline & & 1.5 & 0.0544 & - \\
\hline
\end{tabular}

As seen in Table 4 and 5 and Fig. 2, electrolyte of smaller amount for use and lower f.p. was obtained when methyl alcohol was used as an anti-freezing reagent.

\subsection{Discussion}

\subsubsection{On electrolytes for ordinary temperature}

\section{a) On electrolytes of $\mathrm{NaCl}$ alone}

In the electrolytes of $\mathrm{NaCl}$ alone, self-corrosion amount is small though aluminum of low purity is used independent of their concentration, which will be suitable as the electrolyte of batteries for long life.

\section{b) On the effects of sulfamic acid}

When sulfamic acid is added to $\mathrm{NaCl}$, b.p., f.p., etc. of the electrolyte are not greatly changed from those of the electrolytes of $\mathrm{NaCl}$ alone, but their conductivities are greatly increased compared to those of $\mathrm{NaCl}$ alone.

However, when aluminum of low purity is used, selfcorrosion amount is very large and heat generated at anode by self-corrosion in the cell increased to promote the evaporation of electrolyte.

Therefore, in this case, it will be adequate for the battery to be discharged for a short time in large current to use aluminum of high purity as anode.

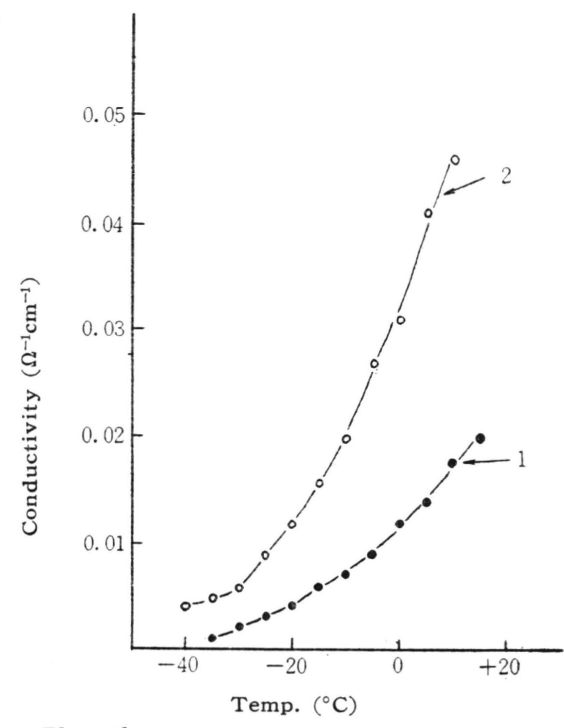

Electrolyte

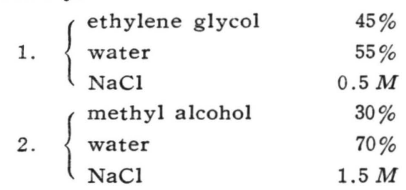

Fig. 2 Relation between temperature and conductuty

\subsubsection{On electrolytes for low temperature}

From the results shown in Table 4 and 5 , it is better to use the mixed solution of methyl-alcohol and water as impregnating liquid, for its f.p. is lower with a smaller amount of anti-freezing reagent and its conductivity is higher.

As mentioned in detail below, in aluminum and magnesium batteries, electrolytes should be antifreezing only at the time of impregnation and the cell gradually rises during the discharge.

Therefore, the evaporation of anti-freezing reagent need hardly be taken into consideration, and it will

* It means conc. of $\mathrm{NaCl}$ in the mixed solution of ethylene glycol and water. 
be practical to use the mixed solution of methyl alcohol and water as impregnating liquid for low temperature.

\section{Conclusion}

In general, electrolytes for batteries have inconsistent properties, namely, without self-corrosion (non-electromotive resolution) they easily dissolve anode metal during the discharge. Moreover, conductivity should be high in order to lower the internal resistance of the battery as much as possible.

The conditions required for the electrolyte of aluminum "Reserve Battery" will be summarized from the results of the experiments in this report and the previous Reports (I) (V).

(1) The reasons why $\mathrm{NaCl}$ alone or mixture of $\mathrm{NaCl}$ and sulfamic acid is selected as the most practical electrolyte are as follows:

a) No chemical change during preservation.

b) Less hygroscopic and good resolution at impregnation.

c) High conductivity.

d) Easily dissolves anode aluminum electromotively, but self-corrosion of anode is considerably small.

e) Low price.

f) Sodium chloride alone is required for the electrolyte of the aluminum battery of small current and long life (small self-corrosion amount of anode aluminum).

g) The mixture of $\mathrm{NaCl}$ and sulfamic acid is required for the electrolyte of the aluminum battery of large current and short life(large reactivity with anode).

(2) For cold-proof electrolyte, anti-freezing reagent such as methanol should be added to the impregnating liquid rather than the selection of electrolytes.

(3) By the construction of aluminum battery and its short life, it can be concluded that the evaporation of water in the electrolyte by the heat of battery gives almost no effects on its discharging power. However, sometimes the reagents such as glycerines which elevate b.p. should be added to the impregnating liquid.

I wish to express my sincere appreciation to Prof. Yoshizawa, Kyoto Univ., and Prof. Mizuguchi, Tokyo Inst. of Tech., for their cordial guidance throughout this research, and also to Mr. K. Ishiyama, Special Managing Director of Toyo Dry Battery Co., and Mr. I. Hirota, Ordinary Managing Director of the above Co., for their permission to publish this paper.

I express my gratitude to Mr. K. Osada for his earnest help in this study.

(Received Sept. 28, 1962)

\section{Literature :}

1) W.J. Schlotter, J. Electrochem. Soc. 99, 205 C (1952); G.W. Vinal, "Primary Batteries" p. 302 (1950). John Wiley \& Sons. Inc.

2) G.W. Vinal, ibid. p. 282 (1950), John Wiley \& Sons. Inc.

3) I.C. Blake, J. Electrochem. Soc. 99, 202 C (1952); G.W. Vinal, "Primary Batteries" p. 274 (1950).

4) L.E. Pucher, J. Electrochem. Soc. 99, 203 C (1952); S. Makino, Seminar-text of Electrochem. Electrochem. Soc. Japan ed. p. 237 (1957); Y. Yokota, Denki-Kagaku 26, 284 (1958);

Morse, Tenth Annual Battery Conference of the Signal Corps. p. 23 (1956).

5) Y. Yokota, Denki-Kagaku 28, 518 (1960). 